\section{Recognizing and Reducing Barriers to Science and Math Education and STEM Careers for Native Hawaiians and Pacific Islanders}

\author{
JoNita Q. Kerr, ${ }^{\dagger}$ Donald J. Hess, ${ }^{\sharp \$ l \|}$ Celia M. Smith, ${ }^{\text {" }}$ and Michael G. Hadfield"* \\ 'Department of Math \& Science, Guam Community College, Mangilao, Guam 96923; 'College of \\ the Marshall Islands, Majuro, Republic of the Marshall Islands, Majuro, MH 96960; "Department of \\ Botany, University of Hawai'i at Mānoa, Honolulu, HI 96822; \#Kewalo Marine Laboratory, Pacific \\ Biosciences Research Center, University of Hawai'i at Mānoa, Honolulu, HI 96813
}

\begin{abstract}
Climate change is impacting the Pacific Islands first and most drastically, yet few native islanders are trained to recognize, analyze, or mitigate the impacts in these islands. To understand the reasons why low numbers of Native Hawaiians and Pacific Islanders enter colleges, enroll in science, technology, engineering, and mathematics (STEM) courses, or undertake life sciences/STEM careers, 25 representatives from colleges and schools in seven U.S.-affiliated states and countries across the Pacific participated in a 2-day workshop. Fourteen were indigenous peoples of their islands. Participants revealed that: 1) cultural barriers, including strong family obligations and traditional and/or religious restrictions, work against students leaving home or entering STEM careers; 2) geographic barriers confront isolated small island communities without secondary schools, requiring students to relocate to a distant island for high school; 3 ) in many areas, teachers are undertrained in STEM, school science facilities are lacking, and most island colleges lack STEM majors and modern labs; and 4) financial barriers arise, because many islanders must relocate from their home islands to attend high school and college, especially, the costs for moving to Guam, Hawai'i, or the U.S. mainland. Most solutions depend on financial input, but mechanisms to increase awareness of the value of STEM training are also important.
\end{abstract}

\section{INTRODUCTION}

The islands of Oceania are at the forefront of the impacts of climate change, especially rising sea level, which takes away land and destroys freshwater aquifers. Yet most of the citizens of these islands are little prepared to understand, mitigate, or adapt to what climate change is doing to their homelands. At the same time, Pacific Islanders are faced with having to maintain sustainable fisheries, solve environmental pollution, provide sufficient water for growing populations, and cope with increasing numbers of visitors. Small colleges across the U.S.-flag territories (American Samoa, Guam, Commonwealth of the Northern Mariana Islands [CNMI]) and the Compact of Free Association (COFA) countries (Republic of the Marshall Islands [RMI], Federated States of Micronesia [FSM], and Republic of Palau—whose citizens have the same rights as U.S. citizens to live, work, and be educated in the United States) work valiantly to educate their students to participate in 21st-century discussions and planning for climate change impacts. However, the colleges lack the capacity-or the time in a 2-year curriculum-to equip students with in-depth training and experience in research necessary to devise immediate and long-term solutions to the environmental crises they face. Similarly, many students of Hawaiian descent are undertrained in hands-on research necessary to participate in efforts to conserve the unique biological elements in their "extinction capital of the world" (e.g., Graham, 2012). Outside of Hawai'i,
CBE Life Sci Educ December 1, 2018 17:mr1 DOI:10.1187/cbe.18-06-0091

sRetired.

"Present address: P.O. Box 3085, Majuro, MH 96960.

*Address correspondence to: Michael G. Hadfield (hadfield@hawaii.edu)

(c) 2018 J. Q. Kerr et al. CBE-Life Sciences

Education (๑) 2018 The American Society for Cell Biology. This article is distributed by The American Society for Cell Biology under license from the author(s). It is available to the public under an Attribution-Noncommercial-Share Alike 3.0 Unported Creative Commons License (http://creativecommons.org/licenses/ by-nc-sa/3.0).

"ASCB $®$ " and "The American Society for Cell Biology $\AA^{\circ}$ are registered trademarks of The American Society for Cell Biology. 
there is only one 4-year college, the University of Guam, with the remaining six island groups providing only 2-year colleges.

Native Hawaiians and Pacific Islanders (NHPI) are perhaps the least acknowledged of four ethnic groups recognized by U.S. government agencies as underrepresented in the fields of science, technology, engineering, and mathematics (STEM). In fact, the inclusion of Pacific Islanders and Hawaiians with Asians in most federal agency initiatives (e.g., White House Initiative on Asian Americans and Pacific Islanders, n.d.) makes it difficult to impossible to obtain precise and up-to-date statistics on the severity of the situation with reference to Pacific Islanders in STEM careers. However, we can determine that Samoans, Chamorros, Marshallese, Micronesians, and Palauans are rarely found in STEM careers for a broad variety of reasons, beginning with training, as indicated by data in many recent documents (e.g., Lee and Kumashiro, 2005). One of the most telling is a report, Education in Pacific Island States: Reflections on the Failure of "Grand Remedies" (Levine, 2015), whose table of contents suggests a multiplicity of causes for the lack of islanders in STEM careers: "Inadequate Funding," "Do Pacific Islanders Value Education?," "Mismatch with Pacific Culture," "Lack of Technical Capacity," "Education as a Source of Public Employment," "Weak Governance," "No Incentives to Improve Efficiency," "Weak Civil Society." Data in this report reveal that problems for many Pacific Islanders begin long before college admittance: "Around 40\% of school children in Pacific Island Countries do not complete primary school, and only $20 \%$ graduate from secondary school." STEM careers are far from the minds of young people who have not even achieved high school diplomas.

For students of Hawaiian ancestry, it is well documented that there are definite economic barriers to education (e.g., Hawai $i$ Papa $\mathrm{O} \mathrm{Ke} A \mathrm{Ao}$, a report presented to the University of Hawai'i Board of Regents, 2012; Tran et al., 2010). Unfortunately, the situation of the Hawaiians in their homeland becomes essentially one of class: many have found themselves near the bottom since annexation of the islands put most land in the hands of powerful white families and, eventually, corporations. Additionally, the Hawaiian population was decimated by common diseases brought to the islands by Westerners. Twohundred-plus years later, Hawaiians living in outlying communities and the smaller islands are still struggling economically. With low incomes, these people find access to STEM careers through higher education difficult to obtain. (Statistics revealing the extent of the problem may be found in the Supplemental Material, Part A.)

Suggesting that cultural practices interfere with education is an unavoidable colonialist bias, because much of the world uses the Western style of education in $\mathrm{K}-12$ and higher education. Conflicts between indigenous cultural practices and Western-style education have always existed, and native peoples have been obliged to yield to the system. Thus, it is not surprising that workshop participants who navigated their way through K-12 and college experienced such conflicts, yet somehow succeeded. Others are failing, because conflicts become barriers. Participants are working to decrease barriers by increasing culturally relevant lessons and training for NHPI teachers and students and acknowledging that NHPI students might follow a somewhat meandering pathway that allows time for family and religion, rather than a straight shot to a degree.
In "A Systematic Review of Barriers and Facilitators to Minority Research Participation among African Americans, Latinos, Asian American, and Pacific Islanders," George et al. (2014, p. e28, italics added) concluded, "Our review of literature points to the need to learn more about and refine our understanding of barriers and facilitators to research participation among African Americans, Latinos, Asian American, and Pacific Islander groups." It was the goal of the workshop upon which this article is based to do exactly that. The workshop took place in June 2016, and this article has been updated to include relevant new data on the situation regarding education and employment opportunities in the Pacific Islands.

\section{WORKSHOP PARTICIPANTS}

To better understand the reasons behind the low numbers of Native Hawaiians and Pacific Islanders entering colleges, enrolling in STEM courses if in college, and going into STEM-relevant careers, the National Science Foundation (NSF) funded a grant to support a 2-day workshop at the University of Hawai'i at Mānoa (UHM) June 1-2, 2016. Invited participants were mostly life sciences instructors from colleges in U.S.-affiliated islands in the Pacific. These instructors from the island colleges are well positioned to recognize and understand the issues that arise from poor or absent STEM training among high school graduates.

Fourteen of the workshop participants are members of the indigenous peoples of their islands in the U.S. flag territories and the COFA countries. Three of the participants were former interns in an NSF minority-training program for undergraduate students at the UHM. Four other participants serve as directors, staff, or evaluators of minority-support programs at their campuses. Two experts in developing minority training programs were invited to address the group, and two NSF program officers observed the workshop. (The names of participants and their professions are provided in the Supplemental Material, Part B.)

\section{CHARGE TO THE PARTICIPANTS}

The workshop began with a presentation by the convener, Michael G. Hadfield, who stressed the two major challenges the group had assembled to address and urged the participants to broadly consider what STEM careers may include: teaching science at any precollege level; teaching college science and math; working in governmental agencies involved with the environment, fisheries, and other natural resources; working for nongovernmental organizations (NGOs) on social and environmental issues; conducting basic research in the lab and field; and working in health fields.

First, the participants were asked to consider the following: What are the barriers causing Pacific Islanders not to seek professional education in STEM areas and enter STEM fields for careers? And, are they truly barriers - that is, things that stand in the way of individuals who want to enter STEM education and careers-or is the lack of participation something different, such as lack of awareness of or lack of cultural value in STEM careers? The group was challenged to consider at least the following factors: cultural barriers that place greater value on other than STEM careers or even aversion to science training; lack of opportunities to learn what scientists and mathematicians do; lack of opportunities due to the isolation imposed 
by the remoteness of many islands from centers of learning; lack of the financial resources necessary for a student to leave home to study in a distant location; and residual colonialism that imposes Western approaches, values, and examples on available education. All of these factors may apply in many situations; for example, the Marshallese residents of Kwajalein Atoll are forced to live on the single islet of Ebeye by the U.S. military that uses the atoll lagoon as a target for missile practice from California and is the primary source of income for the islanders. Very few Ebeye students graduate from high school and even fewer attend college (see Kupferman, 2008; https:// hellomarshallislands.weebly.com/education.html).

Second, participants were asked to focus on the following: What solutions to the problems exposed can we envision? Can barriers be reduced or removed? Can awareness be increased? Can "value" in STEM careers be increased for Pacific Islanders? How?

It should be noted that all workshop participants reviewed this report and provided permission to be quoted in the sections that follow.

\section{PART 1: IDENTIFYING BARRIERS TO STEM EDUCATION AND CAREERS}

Efforts to identify barriers to STEM for NHPI were launched by expert presentations in the area of expanding participation and a panel discussion that included speakers from each of the island groups represented, after which the participants separated into three break-out groups to discuss in depth what the barriers and hindrances for STEM education are across the islands. (Agenda details are presented in the Supplemental Material, Part C.)

\section{Cultural Barriers to Stem Education and Careers}

To understand why there are low numbers of NHPI students in STEM programs and careers, it is necessary to understand how various sociocultural factors such as colonialism, a chief system, religion, and family might influence students' attitudes or career choices. Also, we need to understand what it is about STEM programs or courses that might prevent Pacific Islander students from pursuing them, such as language barriers, lack of intersection between science and culture, and lack of cultural sensitivity of nonnative teachers.

Colonialism and Introduced Religion. The impacts of colonialism cannot be ignored, because the islands represented in the workshop bear a common history of being colonies of conquering nations. The effects of colonial rule and introduced religions are indelibly woven into the mind-set and day-to-day lives of native Pacific Islanders. For example, natives of Guam, the Chamorros, are influenced by Spanish, American, and Japanese rule, and are primarily Roman Catholics. Native Hawaiians remain affected by earlier American rule and Protestant denominations. This report does not attempt to dissect or analyze the effects of colonialism on each of the different Pacific Island cultures, because island groups were ruled by different nations for various lengths of time and to various degrees. However, enough has been written about colonialism to allow that it does shape or modify the sensibilities, behaviors, and attitudes of a people (Hezel, 1982; Diaz, 1994, 2010; Aguon, 2006; Hattori, 2009; de Frutos and Coello de la Rosa, 2012). Indeed, a participant from Hawai'i stated that some students pursuing STEM degrees have become rebellious against educational situations they see as arising from colonialism; for example, students pursuing environmental science, biology, and ecology see the need for greater native cultural perspectives.

Barriers Posed by Chief Systems, Family, Religion, and Stereotype Threats. Respect for parents, elders, chiefs, and others in authority is a dominant feature of Pacific cultures (Hezel, 2013). With the arrival of conquering nations, respect had to be extended to the colonizers, including soldiers, governors, and missionaries. This required practicing the religion and learning the language and culture of the conquering nation or risking punishment (Hattori, 2009; Higuchi, 2001; HawaiiHistory.org [2018], www .hawaiihistory.org/index.cfm?fuseaction=ig.page\&PageID=398). (More information about colonialism and history may be found in the Supplemental Material, Part D.)

Despite colonization and introduced religions, features of traditional culture persist in the islands, such as the chief system and close family relationships. American Samoa, Yap, the Marshalls, Pohnpei, and Chuuk still have chief systems with varying degrees of power and influence. For example, American Samoa has a Polynesian patriarchal chief system that forms the basis of "fa'a samoa, the Samoan way of life" (Johnston, 2010). A workshop participant reported about a student from American Samoa who was preparing to transfer to the University of Hawai'i at Hilo, but was unable to do so when her father was bestowed a high chief title. He commanded her to stay onisland to fulfill her duties as a princess, which was at least a 2-year commitment. Another concern voiced during the workshop is that politics associated with the chief system in American Samoa often discourages college graduates from returning home. This, in turn, reduces the number of native role models and mentors. (More information about the chief system is in the Supplemental Material, Part E.)

Although there is great cultural heterogeneity in Micronesia and Polynesia, a consistently common topic that emerged during the workshop was "family." Close relationships and obligations to immediate and extended family are not merely very important among Pacific Islanders, but as Hezel (2013) describes it, the family is "the heart of the identity of an islander." Family matters take priority over school, and for this reason, many NHPI students find it difficult to succeed in STEM programs. Obligations range from staying at home to care for younger siblings to fulfilling duties if a title is bestowed, such as chief or princess. Often, family obligations are related to religious or traditional practices, including funerals and weddings, that require assistance from all members. Further, seeking higher degrees in science or other fields forces the student to travel hundreds to thousands of miles away, where the student faces culture shock, homesickness, loneliness, and loss of a financial and social safety net, and as a participant stated, "Families just do not want the student to leave."

Workshop participants noted that, for NHPIs, especially citizens of the COFA countries, cultural barriers persist and take on new meaning when they migrate to the United States. Stereotype threats of prejudice and racist attitudes are encountered by Pacific Island students as they try to maneuver in a different culture. Indeed, with more Micronesians moving to Hawai' $i$, as allowed by the COFA agreements, a community usually known 
for its aloha spirit and inclusiveness is becoming increasingly resentful (Blair, 2011; Letman, 2013; Gard, 2017). Many COFA residents now living in Hawai'i, Guam, or the continental United States face discrimination and the misconception that they are a burden on public assistance. For example, with language barriers and few job skills, many COFA migrants encounter unemployment and poverty and are construed as having "poor character" (Hofschneider, 2018). A State of Hawai'i study of different race groups for the years 2011-2015 found that Marshallese migrants had the highest rate of unemployment, $16.9 \%$ versus $6.1 \%$ for the state, and a median household income of $\$ 32,650$ versus $\$ 69,515$ for the state (Department of Business, Economic Development and Tourism, State of Hawai'i, 2018). Despite such figures, COFA migrants pay state and federal taxes that support safety net programs such as food stamps and Medicaid, yet ironically, the migrants do not qualify for those benefits (Letman, 2013: Hofschneider, 2018). Perceived as being at the "bottom of the heap" not surprisingly creates an inferior mind-set in many COFA migrants struggling to survive in Hawai' $i$, Guam, or the U.S. mainland (Letman, 2013; Ridgell, 2016; see "Lessons from Hawaii," by gifted Marshallese poet Kathy Jetnil-Kijiner, www .youtube.com/watch?v=3sbtpazYra0). Thus, for many migrant Pacific Islanders, poverty, prejudice, and discrimination leave few resources or little ambition for seeking a college education, let alone a STEM degree. (More information about the COFA agreements may be found in the Supplemental Material, Part F.)

Language, Relevance, and Connecting Methodology to Island Sensibilities. The Micronesian region includes Palau, the CNMI, Guam, the FSM, the RMI, Nauru, and Kiribati. These politically defined areas include islands that are home to populations that speak distinctly different native languages. The FSM covers an area of 1 million square miles, dotted with 607 small islands that are divided among four states: Chuuk, Yap, Pohnpei, and Kosrae. Although English is the official language, eight major native languages are also spoken-Chuukese, Kosraean, Pohnpeian, Yapese, Ulithian, Woleaian, Nukuoro, and Kapingamarangi (www.visit-micronesia.fm/index.html); additionally, smaller groups of islanders speak Ngatikese, Satawalese, Puluwatese, Mortlockese, and Mokilese. These languages reflect a rich cultural heterogeneity across an area that is more than four times the size of Texas. It is thus no surprise that language can be a barrier, particularly when courses are taught by nonnative teachers.

Another issue that workshop participants cited was the lack of intersection between science and culture. This statement may be examined in three ways. 1) The Western science curriculum has little relevance to the local culture and environment. Improving or modifying the curriculum could be as simple as providing problems or scenarios in an island context. Teaching relevant science to Pacific Islanders requires more place-based texts that explain the rainy and dry seasons, phases of the moon and what they mean in terms of fishing, or the king tides and how they are connected to climate change. 2) Little intersection exists between Western science and indigenous ways of knowing. Western science is based on Aristotle's scientific method of observation, inquiry, and conclusions, yet clearly traditional medicine, agriculture, celestial navigation, and knowledge of seasonal phenomena, such as sea turtle nesting or timing of harvesting certain reef species, are examples of observation-based science-they are just not usually framed as such by scientists and educators (Johannes, 1992; Miller, 2000; Kelson et al., 2003; see also Alessa, 2016). 3) The methodology used to present science is often incompatible with the sensibilities of Pacific Islanders, and many nonnative teachers lack cultural sensitivity to convey the material. Lectures and labs are traditionally used to teach science courses. Teachers expect students to take responsibility for their learning process by asking questions and seeking help if they find that the material is difficult. This approach is fine if the student has been raised in that type of classroom or cultural atmosphere. An explanation of why this type of exchange might not work with islanders is provided by Hezel (2013) in his chapter "Deciphering the Unspoken," in which Micronesians will agree with a statement or accede to a request, not necessarily because they agree, or intend to comply with the request, but because they do not want to disappoint the person who asked the question. One can imagine this familiar scenario when a teacher pauses a lecture and asks, "Do you understand?" or "Are there any questions?" All heads nod in agreement, as the students do not want to disappoint the teacher. Also, replying to a question calls attention to oneself, and others would interpret this as trying to "stand out." Volunteering an answer that could be wrong also risks ridicule by others (Hezel, 2013).

Opportunities in STEM-Related Careers-Awareness and Availability. In Oceania, a large disparity exists with regard to development in terms of industry, infrastructure, and services. In Honolulu, concrete and steel high-rises, traffic, government agencies, private businesses, highly accessible technology, and the associated support services are vastly different from the less developed, less crowded, tranquil villages of Pingelap or Palau. Such differences can influence a population's perceptions and attitudes toward STEM and STEM-related jobs. Islands with a more Western infrastructure, like Hawai'i and Guam, provide a wider variety and number of STEM-related occupations compared with less developed islands. This does not imply that less developed islands do not require such occupations, but few resident people are trained to fill them. Indeed, island nations composed of scattered islands separated by miles of ocean require at least a minimum number of medical personnel, environmentalists, biologists, information technology specialists, STEM educators, disaster managers, engineers, and planners to meet the needs of these populations, particularly as the effects of climate change become more apparent. If such positions are held primarily by nonnative personnel, the perception that only nonnatives qualify for these positions increases-that is, there are few role models of native ethnicity. Also, islanders are often unaware that learning science and math is the path to such positions. To encourage students to take science courses, more support from teachers, family, and government financing at all levels of the process is needed. (Participant comments on cultural barriers are in the Supplemental Material, Part G-1.)

\section{Geographical Barriers to STEM Education}

A significant barrier to students entering STEM disciplines is the sheer enormousness of the geographical area of the Pacific Islands and Hawai'i. The Marshall Islands includes 23 inhabited atolls, comprising 70 square land miles, ranging over 750,000 square miles of ocean, with villages and elementary schools on all of them. However, there are only five high schools across 23 
inhabited islands, meaning that most students must leave home to attend high school on a distant island, and there are many factors that impede a student from doing this (www.worldatlas .com/webimage/countrys/oceania/mh.htm;prism.spc.int/ images/census_reports/Marshall_Islands_Census_2011-Full .pdf)

The FSM comprise more than 600 islands holding approximately 270 square miles of land scattered over 1 million square miles of water (www.fsmgov.org/info/geog.html). Only 164 of the inhabited islands have elementary schools, and just 24 have high schools, again meaning that all students from the small atolls or islands must leave home, travel significant distances, and live with relatives or find boarding to attend high school (www.fsmed.fm/index.php/public-info/education-statistics1; www.micsem.org/pubs/articles/education/frames/edstatsfr .htm).

The Republic of Palau includes 177 square miles of land across 241,000 square miles of ocean. (www.infoplease.com/ country/palau.html). Some of the inhabited islands are connected by roads, so students finishing 11 elementary schools can travel by bus to the single public high school located in the town of Koror. However, students from five other islands not connected by road to Koror must move there and live away from families to attend high school (see www.micsem.org/ schools/palau.htm). Private, parochial high schools are also available, but are located only on the main islands.

\section{The K-12 Education Dilemma as a Barrier to STEM Education and Careers}

Participant college instructors noted that the major barrier to students entering STEM disciplines is the lack of a strong foundation in math, science, and technology in K-12 education. Reasons for this include lack of capacity by teachers, lack of relevant curricula, lack of adequate facilities, and, most fundamentally, a lack of resources. Students need early exposure to science and math to pique their interests in STEM education and careers in the future. STEM will only be relevant to students when it is connected to their lives and their culture. While major shortcomings are noted in many Pacific Island $\mathrm{K}-12$ schools, the comments below are not meant to be seen as criticisms of the hardworking, overloaded teachers who try to educate students in poor facilities and with no relevant materials. Rather, the issues outlined here point strongly to the lack of sufficient funding and material support in most STEM areas.

Inadequate teacher capacity is a big issue for NHPIs. Many of the teachers do not have adequate math or science training themselves. For example, in Palau, nearly $40 \%$ of teachers have only high school diplomas (www.palaumoe.net/phs). In the Marshall Islands, according to the Public School System (formerly the Ministry of Education), as of school year 2015-2016, 158 out of 840 teachers, or 19\%, had only high school degrees (www.rmiembassyus.org/Education.htm). A result is exemplified by this anecdote of an experience related by a faculty member from the College of the Marshall Islands: "An eighth-grade math teacher in the RMI school system, still earning his AS degree at the College of the Marshall Islands, was required to enroll in remedial math, casting doubt that he had sufficient understanding of the basic concepts of math to teach math to eighth graders."
Generally, island teachers lack opportunities to increase their training in STEM. For teachers with only high school diplomas to further their education, intensive workshops or returning to college are the only options. For a teacher to return to school full-time, a replacement teacher is required; there is no pool of qualified people to act as replacement teachers. Teachers might attend college during the summer but would require financial support and a maximum of two classes per summer. It will take a very long time and a lot of support for such individuals to earn even an AS degree. Some of the teachers with only a high school diploma have been teaching for many years, and it is unlikely they would leave their home islands for many successive summers to earn an AS degree, even if financial support was available.

In some Pacific Islands, there are only few grade levels that have teachers teaching only math and science in their classes. Most K-9 classes are self-contained, and teachers teach all subjects for a given grade group of students (English, social science, math, science, etc.). Clearly, they are not specifically trained for most of these pedagogies. Further, many island schools, especially in the remote islands, lack adequate STEM teaching facilities. In the RMI and other island countries that have schools on outer islands, classrooms often consist of only thatched open-air huts, and students of different grade levels are often grouped together and taught by one teacher (https:// hellomarshallislands.weebly.com/education.html). It is hard to appreciate the extent to which resources and technology limit quality education. In outer and remote islands, power outages are frequent, and some island villages have no electricity at all. Simple needs such as fresh water can be scarce, especially in times of drought. Even where accessible, teachers are not being trained to use resources that are available and could serve them well. Additionally, a problem voiced by participants is that access to technology such as computers and the Internet can be difficult or impossible in remote island communities. However, recent developments will provide much needed improvements in Kiribati, Palau, and the FSM (World Bank, 2017).

Many public schools lack a relevant STEM curriculum. Furthermore, many of the education benchmarks have been adopted from Western curricula and not altered to be locally relevant. The textbooks, if the schools even have them, are not something with which students can identify. If students cannot identify with what they are being taught, they probably will not develop an interest in that subject. Many workshop participants from across the Pacific Islands stressed that a "relevant curriculum" is one wherein the teaching materials (e.g., textbooks and charts) are both culturally and geographically appropriate. The world for these students is a tropical atoll with its highest elevation 2 meters above sea level. Lessons that use glaciers to illustrate solid water have missed the educational opportunity to engage students and likely leave them confused. Similarly, texts on governance using the U.S. system would be baffling to a student living in a country where much control of resources is local and matrilineal. Clearly, place-based curricula are important and missing. (Additional participant comments on educational barriers may be found in the Supplemental Material, Part G-2.)

\section{Financial Barriers to STEM Education}

Financial Causes of the K-12 Education Dilemma. Cultural disconnects, geographical barriers, and lack of funding have 
resulted in failures to fund programs that bring high-quality standards, funding, and accomplishments to STEM education for NHPI students in K-12 classes. With little funding, no real progress can be made to bring the NHPI population to federal standards for student accomplishment. The talent pool among these children is high, because at this age, students are, by nature, keen observers of the natural world. Yet lack of opportunities for teachers to receive adequate training, as discussed earlier, limits all children's futures. The major financial barriers for K-12 STEM programs are, first, a lack of funding to allow teacher development to be consistently available in the home institutions in K-12 education; and, second, a lack of funding for student support or mentoring for NHPI students in STEM areas in colleges in their home islands.

Financial Barriers for College Students. The financial barriers that exist for NHPI college students began with their subpar $\mathrm{K}-12$ education. These barriers can be considered "longitudinal deficits," because of poor funding across their educational timelines and pathways to college and their careers. The critical barriers include systemic deficiencies in infrastructure for STEM support at any level, from $\mathrm{K}-12$ to college and postgraduate studies. This barrier to STEM success is geographically biased (i.e., increasing in severity with distance from Hawai'i) and institutions-wide, hampering students throughout their education. As a result of little funding, other dependent situations arise such as: 1) a lack of consistently available teacher development in the home institutions for NHPI students; 2) a lack of consistently available student support or mentoring for NHPI students; 3) a failure to demonstrate how STEM professions are relevant; 4) a lack of coordination across STEM programs to facilitate training and nurturing of all students; and 5) minimal to no advising and opportunities to allow career planning for NHPI students via internships.

It became clear during the workshop that individual faculty and students have been able to make differences, but this is the work of a few, rather than a broad-based program geared to system-wide changes across the educational framework of Pacific institutions from kindergarten to higher education at colleges and universities.

A Closer Look at Dependent Situations Impacted by Drastically Inadequate STEM Funding. A first gap is the lack of funding to make teacher development consistently available in the home institutions for NHPI students. In past years, very few NHPI students who participated in a previously funded NSFURM program (Undergraduate Research Mentoring in the Biological Sciences) came to the University of Hawai'i with backgrounds sufficient to teach in K-12 schools. Few knew the approach to framing hypothesis-driven research, had the tools to develop place-based research, or were ready for STEM jobs in their home economies.

Second, a lack of funding for consistent financial student support for STEM mentoring is a fundamental barrier; students are not given the opportunity to identify themselves as scientists. That identity is one of the best predictors of long-term success. During this workshop, Dr. John Matsui provided an insightful overview of the Biological Scholars Program (BSP) at the University of California at Berkeley (UC Berkeley) (bsp .berkeley.edu). The BSP shows the positive impact of providing an interface between the educational community and those minority students who want to explore STEM, biology in particular, for a bachelor's degree. Students in the program are provided with special advising and counseling from mentors trained to understand special problems experienced by students from underrepresented minorities. The advising is tuned to recognize cultural differences in backgrounds and sensitivities and to assist the students to build on these differences rather than be afraid of them. The students themselves provide powerful peer support for science endeavors. Providing the trained faculty mentors for such a program is expensive, as is providing the space for it. However, the result is a much higher retention and graduation rate for minority students majoring in biology at UC Berkeley. The underlying strategy of developing a critical mass and building long-lived institution-funded communities of mentors and mentees has not even been attempted by any 4-year undergraduate-serving institution enrolling significant numbers of NHPI students.

Summer STEM internships for island students in universities provide another model for increasing STEM proficiency. Nearly 20 years of experience with NSF-funded internship programs for predominantly NHPI students at UHM has provided some workshop participants knowledge of the value of one-on-one research mentoring. Such internships, even for periods as brief as 10 weeks, allow previously undertrained and naïve island interns with knowledge to understand that they are scientists, with the ability to complete baccalaureate degrees and go on to careers in STEM fields and advanced degrees, especially in the life sciences. Former interns in these programs now teach in island schools and colleges and work for environmental agencies or NGOs on their home islands. Despite the presence of programs such as UC Berkeley's BSP and the University of Hawai'i's NSF-supported UMEB, URM, and Research Experiences for Undergraduates (REU) programs, income inequality-low levels of incomes for NHPI students-is a real threat to their STEM success, because low family income can prevent students from taking advantage of programs that are available in select locations such as existing NSF REU opportunities. Despite this encouraging progress, many NHPI students work to support their families. Even a program that pays a stipend may not cover wages lost during an REU, leaving a lasting negative impact on their families.

A third financial deficiency is the lack of funding for programs that highlight STEM professions as relevant careers for NHPI students, their families, and communities. There is no clearinghouse for general information or internships in STEM across these minority groups. Internship clearinghouses are often run by student centers, home departments, or other student-oriented programs on major campuses. Not having a specialized internship program for NHPI means that students are neither recruited nor placed in federal or agency offices across the Pacific region. This lack of professional development is acceptable only if you dismiss the possibility of STEM careers in the Pacific Islands. However, the numbers of STEM jobs in educational institutions, NGOs, agriculture, fisheries, weather science, and reef health increases yearly, and their importance has jumped proportionally with global change challenges. Pacific region-based scientists are needed now more than ever to ensure that best management decisions are made to preserve cultural practices and islanders' ways of life. For example, decision makers at the United Nations and elsewhere are trying 
to put together legal frameworks in support of assembling floating oil rig-like structures or "lilypads" to replace islands that will be inundated with rising sea levels (https://vincent .callebaut.org/page1-img-lilypad.html). Plans for lilypads make no provision to sustain the fishing culture known throughout the Pacific. The voices of these island peoples need strong scientific content for their responses to be heard over the wellintended but out of touch planning by dominant political groups. Having substantial upgrades in the quality of professional development among teachers in K-12 and NHPI-serving colleges and universities is essential.

A final, fourth, financial gap is the lack of funding for a system-wide infrastructure for college and postgraduate studies in large parts of the U.S. Pacific region. In reality, there is no facilitation for inter-institution exchanges that could lead to networking for Pacific-region educators and students. Such disconnects are profound and lead to students not getting scholarship funds in time to make payments at other institutions and causing them to face academic probation. There is a lack of travel funds or programs to facilitate taking courses at other institutions. Records are full of students who transfer from the island community colleges (e.g., College of Micronesia) to UHM and find that their course credits, while accepted as credit-hours, are not accepted by departments as counting toward their majors. Thus, to finish with a BA or BS in a STEM major at UHM means that a transfer student from Palau, the RMI, or the FSM faces three to four additional years of course work and the associated costs. This lack of Pacific-wide integration creates a second-class tier of college students when those students attempt to compete in national programs. (Additional participant comments on financial barriers may be found in the Supplemental Material, Part G-3.)

\section{Part 2: Identifying Solutions-How to Remove the Barriers to STEM Education and Careers for Native Hawaiians and Pacific Islanders}

Each of the following sections deals with one of the major barrier categories developed during the workshop: culture, geography, education, and finance. It can be asked, to whom are these recommendations directed? Clearly, other than cultural issues, most involve either education (of students or the populace of each island group) or money. Thus, the recommendations are most important for local agencies (e.g., departments of education) in each island group and legislators who hold the power of appropriation. The workshop participants also anticipate that this paper and these recommendations will be read by administrators at major state and federal funding agencies (e.g., the NSF).

It was recognized that many of the cultural barriers arise or persist because of inadequate training or education. Thus, there is overlap in the recommendations for reducing cultural barriers and educational barriers to STEM education, as reflected in the two following sections. Similarly, many of the educational barriers can only be addressed by funding.

1. Overcoming or reducing cultural barriers. Participant recommendations for overcoming cultural barriers are summarized in Table 1.

2. Coping with geographical barriers. The obvious solution to most geographical barriers to STEM education is improving the airline and shipping schedules and reducing their costs so students can attend a high school when there is none on
TABLE 1. Recommendations for overcoming cultural barriers

Engage families in students' education with "talk-story" opportunities with native mentors or role models who have successfully navigated STEM programs.

Train mentors to be knowledgeable about and sensitive to the cultural backgrounds of their Pacific Island students.

Institute public education programs to reach across generations to inform island residents about the imminent problems of climate change and sea-level rise in the Pacific Islands, as well as the acuteness of issues regarding environmental and resource conservation.

Recognize the cultural and familial obligations of Pacific Islander students by allowing them time to tend to such obligations when they arise and acknowledging that working toward a STEM degree or career is more like a pathway than a straight 4-year program.

Provide safe spaces on campuses for students far from home and family, where they can escape stereotype threats by meeting and finding social and emotional support among one another.

their home island. However, this is not realistic, as it would be extremely expensive. Thus, participants at the workshop recommended that island high schools must be subsidized to support residences for students who are away from home and to underwrite the costs to get to the islands where the high schools are located. This problem is especially pronounced in American Samoa, the RMI, FSM, and Palau, and these island groups assuredly need the most financial assistance for this improvement mechanism. Although a partial solution to this could be through advanced technology, not all of the islands have the infrastructure to provide Internet or distance education.

3. Improving $\mathrm{K}-12$ education: reducing the $\mathrm{K}-12$ dilemma. As noted earlier, one of the main barriers to increasing the numbers of NHPI students attending college and taking STEM courses is the lack of capacity of $\mathrm{K}-12$ faculty to teach most STEM disciplines to precollege students, especially in the lower grades. Currently, in many of the island groups, training for teachers is restricted to English and math. This training needs to be expanded to science and technology. Teachers lacking proper credentials need to be provided with opportunities to complete their college educations. This requires time and funding. At this time, teachers who are not near a college can take courses only in the summer and only two at a time. At that rate, it takes too long for them to complete degrees. Participant recommendations for reducing teaching and faculty-training problems are summarized in Table 2.

4. Removing the financial barriers to achieving college-level training and experience in STEM fields. The participants agreed it would be easy to say, "All we need is funding and everything for STEM education will turn out okay." Yet they insisted that to develop NHPI student talent and potential for the future, there is great need for both short-term and long-term planning that includes steps to fund students to express, not suppress, their cultural backgrounds while working in science. Participant recommendations for reducing financial barriers to STEM are summarized in Table 3.

5. Creating an NHPI student-scientist organization. To continue the momentum of this workshop, participants suggested forming a "society" for NHPI scientists, educators, and students that would be similar to the Society for 
TABLE 2. Recommendations for reducing teaching and faculty-training problems

Bring qualified teachers from the outside to teach classes while the current teachers complete their degrees full time. This will require funding for the outside teachers to be hired, including costs for transportation and housing, as well as salaries. There are organizations that can provide teachers, such as World Teach (https://worldteach.org).

Expand the concept of summer camps for teachers as well as students (e.g., the Alaska Native Science Project, www.ansep.net). Such camps for teachers could concentrate on science, math, and technology, with teachers practicing a "place- and project-based" curriculum incorporating cultural sensitivity. This will aid teachers that have degrees but need to improve their abilities to teach in specific areas such as science, math, and technology (see Uluakea at UH Hilo, https://kipuka.uhh.hawaii.edu/wipce2014/docs/Uluakea\%20Presentation.pdf).

Employ specially trained tutors in the schools to help students in STEM curricula. The tutors could be either current students or graduates who work with the faculty and students. This would help faculty in the development of their capacity and advance their students too.

At the schools, conduct teachers' "brown bag" meetings so they can share ideas and help one another. Here, the teachers can meet and discuss techniques, curricula, and methodologies. This can help not only with content, but more importantly, with delivery. Teachers can exchange ideas and discuss what works and what does not work.

Provide funding for teachers to attend regional or international workshops/trainings with the goal of building capacity. This would help the isolated teachers expand their knowledge to understand what others are doing to address similar problems and how to solve these problems.

Ensure that teachers can work within their environment. Train teachers to be innovative and creative and to understand that learning is not limited to the classroom and that the environment around them is available to help students understand and learn.

Redesign and realign curricula and textbooks to accomplish the ideas of working in the island's culture and environment. An excellent example is a curriculum developed by Professor Linda Furuto at UHM for "Pacific ethnomathematics" (Furuto, 2014). (A partial list of existing place- and culture-based materials may be found in the Supplemental Material, Part H.)

Provide middle and high school science teachers with training or professional development that integrates local history, culture, and language into science and math courses.

Connect STEM courses to careers other than the usual medical, engineering, or academic pathways; introduce students to options such as forestry, agriculture, disaster management, community or urban planning, environmental consulting, and technical positions in local and federal agencies.

Foster multiple communities of interested, motivated students who identify themselves as scientists yet retain their cultural identities and continue to fulfill their familial obligations. These communities should be led by motivated mentors who will create dynamic but supportive workspaces for these students. Funding will be necessary for all aspects of this, especially for mentoring and coordination of services for the students.

Advancement of Chicanos/Hispanics and Native Americans in Science. Such an organization would recognize the unique challenges faced by those of NHPI descent and provide opportunities to overcome barriers recognized by this workshop. Therefore, this resolution should be implemented:

Form and organize a NHPI Society to encourage networking between NHPI scientists and students and provide a clearinghouse for scholarship and grant opportunities. This society would also bridge the gap between STEM and culture by sharing information, knowledge, and inspirational stories of successful NHPI students and scientists.

\section{CONCLUDING REMARKS}

The tropical Pacific islands are home to an incredible and unique diversity of natural habitats and ecosystems. From the barren heights of Hawai'i Island's massive volcanoes to the beautiful islets and lagoon atolls of Samoa, the RMI, the FSM, and Palau are found dry forests, rain forests, tropical jungles, and coral reefs. Living on these islands are the descendants of pioneers who came in open canoes across the entire Pacific

\section{TABLE 3. Recommendations for reducing financial barriers to STEM training and careers}

Support programs that provide financial assistance for mentorships in research-educational centers. Despite the barriers outlined earlier, there are students at the island colleges whose interest in science is evident but hindered, because the colleges lack the time, training, and facilities to provide essential experiences for students. There is no better way to do that than through mentored internships at research universities.

Provide residential tuition rates at colleges across the Pacific and take steps to increase articulation and communication so that students can easily move from one campus to another among the island states. This should be done under the auspice of a Pacific-wide consortium (e.g., create a NHPI STEM Consortium) that unifies STEM education and assessment programs to provide cohesiveness and coherence with the STEM experience. Such a network could create pathways for internship positions for STEM via partners and federal and local agencies and could coordinate across and within participating campuses.

Build a program that can loan funds from one institution (e.g., College of the Marshall Islands) to another (e.g., UHM) just as major universities have a "prior approval" process that makes grant funds available to support incoming island students.

Implement a minority program across U.S.-affiliated Pacific Islands, where the educational institutions build capacity to loan funds to qualified NHPI students, much like the UHM's prior approval process, in which a 90-day early start is allowed and funds are advanced while students wait for federal funds to arrive. This program would provide an almost immediate safety net for many NHPI students who are enrolled in STEM programs but at risk from costly institutional delays.

Raise stipends to meet true costs on the family for NSF-REU participation by a NHPI student.

Assist promising students who lack adequate preparation by providing tutoring services. Extra time should be allowed to make up course deficiencies. 
Ocean thousands of years ago. They established ways of life and unique cultures beautifully and sustainably adapted to the environments where they settled. These practices included navigation, fishing, harvesting, and farming. Belief systems and family cultures were also adapted to life in the very different islands where they lived. However, these habitats are now undergoing rapid changes unlike any experienced by the islanders in the past. The results of global climate change, brought on by no acts of the Pacific Islanders themselves, are drastically impacting the islands before being felt in the "developed" parts of the world. Rising sea levels are eroding the islets of atolls, encroaching on the villages, and flooding the shallow freshwater tables with salt. A first impact of the latter is the destruction of traditional farming, one example being taro, an island starch staple. Rising sea levels have already forced people in the Cartaret Islands to abandon their home islands to seek new homes on the nearby high islands. The national government of Kiribati is investing in large land tracts in Fiji to prepare for migrations from their flooded islands. Pohnpei Island has seen its coastal islands flooded during king tides, and the people of Majuro Island, capital of the Republic of the Marshall Island, have watched their graveyards being washed into the sea. Rising sea level also impacts the coral reef habitats of nearly all Pacific islands, disrupting the entire coastal ecology and the habitats of the fishes that have formed the major dietary protein for many islanders.

On top of the changes wrought by rising sea levels and the 20th- to 21st-century add-ons of pollution, introduced materials that change lifestyles (e.g., canned foods and disposable, but nonbiodegradable wastes), and the losses of important land to U.S. military bases in the Marshall Islands, Guam, and Hawai'i, is the sad reality that the traditional practices and traditions of the Pacific Island cultures do not adequately protect the people attempting to cope with the destructive changes engulfing them. For the wide variety of reasons exposed during the deliberations of this workshop, abundant and ready access to the methods and practices of modern math, science, and technology are too limited in their availability to the native peoples of the islands.

It is anticipated that the recommendations from this workshop can be used broadly to devise and implement changes that will lead to increased participation of Native Hawaiians and Pacific Islanders in science, technology, engineering, and technology training, from $\mathrm{K}-12$ through college degrees and entry into relevant careers that employ these skills. Young, culturally sensitive people from the island cultures are essential to confronting the changes coming at them and in arriving at ways to mitigate those changes.

\section{ACKNOWLEDGMENTS}

The success of this workshop depended on the support of many people in addition to the enlightening efforts of the invited participants. Ms. Dawn Chang organized and led an outstanding team of facilitators whose management in the workshop discussions contributed immeasurably to its success. The team included Anne Marie Smoke of the Matsunaga Institute for Peace and Conflict Resolution at the University of Hawai'i and her associates who participated in the session facilitation and recording of proceedings, especially Jose Barzola and Kathryn Ranney. Nancy L. Marker, educational specialist, Social Science Research Institute, UHM, participated in the workshop and provided valuable feedback as this report was being prepared. Ms. Shari Goudreault of the Pacific Biosciences Research Center provided essential assistance in all aspects of arranging housing for participants, venues for the meetings, and meals. Dr. Brad Jones of the Pacific Biosciences Research Center video-recorded the proceedings and made them available in multiple forms following the workshop. Dr. David Karl, director, Center for Microbial Oceanography: Research and Education, University of Hawaili, provided support for transporting all participants between hotels and the University of Hawai'i campus during the workshop. Colleagues in the Hadfield Laboratory provided essential logistical support during the workshop: Marnie Freckelton, Kimberley Lema, Brian Nedved, Melissa Price, and Nidhi Vijayan. The workshop was supported by National Science Foundation grant no. 1638738 to M.G.H.

\section{REFERENCES}

Aguon, J. (2006). Just left of the setting sun (p. 85). Tokyo, Japan: Blue Ocean Press

Alessa, L. N. (2016). The Other Way of Knowing. Schooling the World Retrieved September 25, 2016, from https://schoolingtheworld.org/ resources/essays/the-other-way-of-knowing

Blair, C. (2011, June 10). No aloha for Micronesians in Hawaii. Civic Beat Retrieved from www.civilbeat.org/2011/06/no-aloha-for-micronesians -in-hawaii/

de Frutos D. A., \& Coello de la Rosa, A. (2012). Death rituals and identity in contemporary Guam (Mariana Islands). Journal of Pacific History, 47(4), 459-473.

Department of Business, Economic Development and Tourism, State of Hawai'i. (2018). Demographic, Social, Economic, and Housing Characteristics for Selected Race Groups in Hawaii. Retrieved March 25, 2018, from files.hawaii.gov/dbedt/economic/reports/SelectedRacesCharacteristics _HawaiiReport.pdf

Diaz, V. M. (1994). Simply Chamorro: Telling tales of demise and survival in Guam. Contemporary Pacific, 6(1), 29-58. Retrieved August 20, 2016, from https://hdl.handle.net/10125/12956

Diaz, V. M. (2010). Repositioning the missionary: Rewriting the histories of colonialism, native Catholicism, and indigeneity in Guam (p. 256) (Pacific Islands monograph series 24). Honolulu: University of Hawai'i Press.

Furuto, L. H. L. (2014). Pacific ethnomathematics: Pedagogy and practices in mathematics education. Teaching Mathematics and Its Applications, 33(2), 110-121.

Gard, A. R. (2017). Looking for light on the dark side of the American dream-Exploring the painful legacy of nuclear colonialism in paradise. International Journal of Research in Sociology and Anthropology, 3(4), $32-42$

George, S., Duran, N., \& Norris, K. (2014). A systematic review of barriers and facilitators to minority research participation among African Americans, Latinos, Asian Americans and Pacific Islanders. American Journal of Public Health, 104(2), e16-e32.

Graham, F. (2012). Hawaii's Silent Extinction. Audubon. Retrieved March 25, 2018, from www.audubon.org/news/hawaiis-silent-extinction

Hattori, A. P. (2009). Colonialism, capitalism and nationalism in the US Navy's expulsion of Guam's Spanish Catholic priests, 1898-1900. Journal of Pacific History, 44(3), 281-302.

Hezel, F. X. (1982). From conversion to conquest: The early Spanish mission in the Marianas. Journal of Pacific History, 17, 115-137. Retrieved August 16, 2016, from www.micsem.org/pubs/articles/historical/frames/convconfr htm

Hezel, F. X. (2013). Making sense of Micronesia: The logic of Pacific Island culture (p. 182). Honolulu: University of Hawai'i Press.

Higuchi, W. (2001). The Japanisation policy for the Chamorros of Guam, 1941-1944. Journal of Pacific History, 36(1), 19-35.

Hofschneider, A. (2018, March 27). Racial inequality in Hawaii is a lot worse than you think. Civic Beat. Retrieved March 29, 2018, from www.civilbeat .org/2018/03/racial-inequality-in-hawaii-is-a-lot-worse-than-you-think 
Johannes, R. E. (1992). Words of the lagoon: Fishing and marine lore in the Palau District of Micronesia (p. 320). Berkeley: University of California Press.

Johnston, R. (2010, January). Chief communications: Communication and cultural practices among Samoan Matais. Journal of Intercultural Communication, issue 22. Retrieved August 14, 2016, from www.immi.se/ intercultural

Kelson, K. P., Bartram, P. K., \& Friedlander, A. M. (2003). The use of traditional Hawaiian knowledge in the contemporary management of marine resources. In Haggan, N., Brignall, C., \& Wood, L. J. (Eds.), Putting fishers' knowledge to work, conference proceedings August 27-30, 2001 (pp. 328-339) (Fisheries Centre research report, vol. 11, no. 1). Retrieved from https://open library.ubc.ca/cIRcle/collections/ubccommunityandpartnerspublicati/ 37052/items/1.0074793

Kupferman, D. W. (2008). No Western agenda left behind: A comparative analysis of higher education institutions in the Republic of the Marshall Islands. International Journal of Learning, 15(2), 69-77.

Lee S. J., \& Kumashiro K. K. (2005). Asians and Pacific Islanders: Education Issues. Retrieved March 25, 2018, from www.nea.org/home/15571.htm

Letman, J. (2013, October 3). Micronesians in Hawaii face uncertain future. Al Jazeera. Retrieved March 26, 2018, from www.aljazeera.com/ humanrights/2013/10/micronesians-hawaii-face-uncertain-future $-201310191535637288 . h t m l$

Levine, V. (2015). Education in Pacific Island states: Reflections on the failure of "grand remedies." Honolulu, HI: East-West Center. Retrieved
March 25, 2018, from www.eastwestcenter.org/system/tdf/private/ pip008_0.pdf?file=1\&type=node\&id=33999

Miller, J. (2000). Listening to the elders. Marine Turtle Newsletter, 88, 1-2. Retrieved September 25, 2016, from www.seaturtle.org/mtn/archives/ $\mathrm{mtn} 88 / \mathrm{mtn} 88 \mathrm{p} 1 . \mathrm{shtml}$

Ridgell, C. (2016). We are the lowest of all Micronesians But We Just Need a Little Bit of Your Respect as Human Beings-Berth Diamond. Pacific News Center. Retrieved June 1, 2018, from https://pacificnewscenter .com/we-are-the-lowest-of-all-micronesians-but-we-just-need-a - little-bit-of-your-respect-as-human-beings-bertha-diamond/

Tran, J., Wong, M., Wright, E. K., Fa'avae, J., Cheri, A., Wat, E., ... Foo, M. A (2010). Understanding a Pacific Islander young adult perspective on access to higher education. Californian Journal of Health Promotion, 8 , $23-38$.

University of Hawai'i. (2012). Hawai'i Papa O Ke Ao. Retrieved March 25, 2018, from www.hawaii.edu/offices/op/hpokeao.pdf

White House Initiative on Asian Americans and Pacific Islanders. (n.d.) Fact sheet: What you should know about Native Hawaiians and Pacific Islanders. Washington, DC. Retrieved March 25, 2018, from www2.ed.gov/ about/inits/list/asian-americans-initiative/what-you-should-know.pdf

World Bank. (2017, June 1). Remote Pacific regions set for broadband Internet under new World Bank projects. Retrieved March 25, 2018, from www.worldbank.org/en/news/press-release/2017/06/01/remote -pacific-regions-set-for-broadband-internet-under-new-world-bank - projects 